\title{
PENINGKATAN PRODUKTIVITAS KERJA DOSEN MELALUI PENGEMBANGAN EFEKTIVITAS SISTEM INFORMASI MANAJEMEN DAN BUDAYA ORGANISASI
}

\author{
Annisa Restu Purwanti ${ }^{1}$, Nandang Hidayat $^{2}$, Entis Sutisna ${ }^{2}$ \\ ${ }^{1}$ Pegawai Universitas Muhammadiyah Sukabumi, Jawa Barat \\ ${ }^{2}$ Program Pascasarjana Universitas Pakuan \\ Email :pasca@unpak.ac.id
}

\begin{abstract}
This study aims to find out how the productivity of lecturers can be enhanched by developing the effectivity of management information system and organizational culture. Population taken for this research is lecturer at Muhammadiyah University of Sukabumi with status of permanent Lecturer. There are 134 lecturers and they are taken 101 lecturers as samples. Questionnaire is used to collect the data. Data analysis techniques used descriptive analysis, correlation, partial and double regression. Hypothesis testing is performed at the level of significance 0.05. The results show that there is a significant positive relationship between effectiveness of management information systems and lecturer's performance productivity $\left(r_{y 1}=0,342\right)$, there is a very significant positive relationship between organizational culture with lecturer's performance productivity $\left(r_{y 2}=0,327\right)$, and there is a higly significant positive relationship between effectiveness of management information systems and organizational culture together with lecturer's performance productivity $\left(r_{y 12}=0,367\right)$. Thus, it can be concluded that lecturer's performance productivity can be enhanced through effectiveness of management information systems and organizational culture either partially or together.
\end{abstract}

Keywords: effectiveness of management information systems, organizational culture, and lecturer's productivity

\begin{abstract}
ABSTRAK
Penelitian ini bertujuan untuk mengetahui bagaimana produktivitas kerja dosen dapat ditingkatkan melalui efektivitas sistem informasi manajemen dan budaya organisasi. Populasi yang diambil untuk penelitian ini adalah dosen di Universitas Muhammadiyah Sukabumi dengan status Dosen tetap yang berjumlah 134 dosen dengan sampel berjumlah 101 dosen. Pengumpulan data untuk setiap variabel penelitian menggunakan kuesioner. Teknik analisis data menggunakan analisis deskriptif, korelasi, regresi parsial dan ganda. Pengujian hipotesis dilakukan pada taraf signifikansi 0,05 . Hasil penelitian menunjukkan bahwa terdapat hubungan positif yang signifikan antara efektivitas sistem informasi manajemen dengan produktivitas kerja dosen $\left(r_{y 1}=0,342\right)$, terdapat hubungan positif yang sangat signifikan antara budaya organisasi dengan produktivitas kerja dosen $\left(r_{y 2}=0,327\right)$, dan terdapat hubungan positif yang sangat signifikan antara efektivitas sistem informasi manajemen dan budaya organisasi secara bersama-sama dengan produktivitas kerja dosen $\left(r_{y 2}=0,327\right)$. Dengan demikian dapat disimpulkan bahwa produktivitas kerja dosen dapat ditingkatkan melalui efektivitas sistem informasi manajemen dan budaya organisasi baik secara parsial maupun bersama-sama.
\end{abstract}

Kata kunci: efektivitas sistem informasi manajemen, budaya organisasi, dan produktivitas kerja 


\section{PENDAHULUAN}

Pembangunan suatu bangsa ditandai dengan kualitas sumber daya manusianya. Peningkatan kualitas sumber daya manusia menjadi titik tolak dalam pembangunan bangsa. Upaya peningkatan kualitas sumber daya manusia di Indonesia salah satunya melalui peningkatan mutu pendidikan baik pada jenjang dasar, menengah maupun pendidikan tinggi.

Perguruan tinggi diharapkan mejadi pusat penyelenggaraan dan pengembangan pendidikan tinggi serta menyebarluaskan ilmu pengetahuan, teknologi, dan kesenian serta mengoptimalkan penggunaanya untuk meningkatkan taraf hidup masyarakat dan memperkaya kebudayaan nasional melalui pengabdian pada masyarakat. Tugas dan fungsi dosen sebagai sumber daya perguruan tinggi memiliki nilai tinggi dalam setiap aktivitas dan karya ciptanya. Mengembangkan dan menyebarluaskan ilmu pengetahuan melalui pendidikan, penelitian, dan pengabdian kepada masyarakat merupakan tugas utama seorang dosen Tugas melaksanakan tridharma perguruan tinggi merupakan satu kesatuan dharma karena saling terkait dan mendukung satu sama lain. Oleh karena itu, produktivitas seorang dosen dalam penelitian dan publikasi menjadi tolok ukur utama yang menggambarkan profesionalisme dosen sebagai ilmuwan. Karena salah satu indikator mutu pendidikan tinggi adalah sejauh mana dosen produktif dalam melaksanakan tugas dan fungsinya..

Adapun di jaman teknologi, sistem informasi yang terus berkembang menjadi suatu kebutuhan dalam mencapai sasaran kinerja yang efektif dan efisien. Sistem nilai, kebiasaan dan lingkungan kerja mendorong adanya apresiasi terhadap diri dan persepsi diri dalam meningkatkan prestasi kerja. Dengan ini, diduga terdapat hubungan antara produktivitas kerja dosen dengan efektivitas sistem informasi manajemen dan budaya organisasi.

\section{Produktivitas Kerja}

Produktivitas kerja dosen berkaitan erat dengan tugas dan fungsi dosen dalam menjalankan tridharma perguruan tinggi. Muchdarsyah (2000:17-18) mendefinisikan produktivitas adalah suatu pendekatan interdisipliner untuk menentukan tujuan yang efektif, pembuatan rencana, aplikasi penggunaan cara yang produktif untuk menggunakan sumbersumber secara efisien, dan tetap menjaga adanya kualitas yang tinggi.

Produktivitas kerja merupakan kemampuan dalam menghasilkan sesuatu dalam pekerjannya yang menekankan pada hasil luaran yang berkualitas dengan mendayagunakan masukan yang ada secara efektif dan efisien. Seperti yang diungkapkan Lubis (2012: 74), Eviyan Ihsani, dkk (2017:6), Engkoswara dan Komariah (2010: 39), Lubis (2012: 74), Suwena (2008: 10) mendefinisikan produktivitas kerja adalah hasil kemampuan dalam mendayagunakan sumber daya yang dimiliki untuk menyelesaikan tugas pekerjaan berkaitan dengan kualitas hasil kerja, kuantitas hasil kerja, efektivitas kerja, dan efesiensi kerja, diukur melalui perbandingan hasil yang dicapai dan sumber daya yang digunakan.

Berdasarkan kajian terhadap teori-teori produktivitas kerja dapat disintesiskan bahwa produktivitas kerja dosen adalah capaian hasil dari segenap potensi dosen dengan mendayagunakan sumber daya yang dimilikinya dihubungkan dengan waktu, kuantitas dan kualitas dalam melaksanakan tugasnya menjalankan tridharma perguruan tinggi.

\section{Efektivitas Sistem Informasi Manajemen}

Siagian (2001:24) Efektivitas menunjukan keberhasilan dari segi tercapai atau tidaknya sasaran yang telah ditetapkan. Fahmi (2013:77), Laudon dan Laudon (2008:22), Joko (2010:148), McLeod dan Schell (2008: 12), Hamalik (1995:15-16) mengemukakan definisi sistem informasi manajemen merupakan sekumpulan komponen perangkat keras, perangkat lunak, database, prosedur, petugas yang saling berhubungan, mengumpulkan (atau mendapatkan), memproses, menyimpan, dan mendistribusikan informasi menjadi sesuatu yang 
berguna bagi setiap lini manajemen sebagai menunjang pengambilan keputusan dan pengawasan dalam organisasi. Efektivitas sistem informasi manajemen merupakan ukuran yang memberikan gambaran sejauh mana target dapat dicapai dari kumpulan sumber daya yang diatur untuk mengumpulkan, memproses, dan menyimpan data yang kemudian mengubahnya menjadi sebuah informasi yang berguna serta menyediakan laporan yang dibutuhkan menjemen dengan baik secara kualitas maupun waktu.

Efektif atau tidaknya suatu sistem informasi dirasakan langsung oleh penggunanya, apakah output yang dihasilkan dapat bermanfaat atau tidak. Hal tersebut dapat tercapai dengan disediakannya informasi yang sesuai dengan kebutuhan baik dalam jumlah, kualitas, waktu, maupun biaya. Ada beberapa persyaratan agar informasi yang dibutuhkan dapat bermanfaat bagi para pengambil keputusan dan pengguna lainnya menurut Muctaram dan Suryadi (2010:158) yaitu uniformity, lengkap, jelas, dan tepat waktu. Sistem informasi manajemen yang dikelola dengan baik akan mampu memberikan dampak dalam meningkatkan produktivitas organisasi. Efektivitas sistem informasi yang baik akan memberikan arti bagi penggunanya

Dari beberapa kajian terhadap teori-teori efektivitas sistem informasi manajemen dapat disintesiskan bahwa efektivitas sistem informasi manajemen adalah ukuran yang menunjukan ketepatan penerapan sistem informasi dapat memberikan hasil dan manfaat yang sesuai dengan yang diharapkan pengguna.

\section{Budaya Organisasi}

Budaya organisasi merupakan kepribadian organisasi. Budaya organisasi sangat penting dalam membangun organisasi yang efisien (Hidayat dkk, 2018). Widjaja (2006:91), Creemers dan Reynold (1993), Siagian (2009:187), Schein (2012:128), mengemukakan yang dimaksud dengan budaya organisasi adalah seperangkat keyakinan, asumsi, nilai-nilai, perasaan dan persepsi yang mempengaruhi tindakan dan keputusan anggota organisasi dalam kehidupannya berorganisasi. Budaya terkait dengan persepsi. Robbins (2006: 169) berpendapat persepsi merupakan cara pandang seseorang dalam menangapi suatu hal. Simamora (2002: 102) menyatakan bahwa persepsi merupakan pandangan seseorang yang membentuk pemahaman seperti apa yang berujung pada tindakan.

Pandangan, sikap dan perilaku anggota organisasi dipengaruhi oleh nilai budaya yang ada di dalam organisasi. Budaya organisasi menurut Sedarmayanti (2007: 76) menawarkan suatu sistem bersama mengenai arti, dimana menjadi dasar untuk komunikasi dan pemahaman bersama. Jika fungsi ini tidak direalisasikan dalam suatu cara yang layak, budaya mungkin secara signifikan mengurangi efisiensi organisasi. Budaya organisasi muncul dalam bentuk tindakan dan perilaku dari setiap organisasi. Perilaku tersebut mempunyai relevansi tinggi dengan kemauan, kemampuan dan kesediannya dalam meningkatkan produktivitas kerja sehingga budaya organisasi menggerakan dan mengendalikan interaksi anggota organisasi dalam aktivitas kerja yang dapat dijadikan sebagai salah satu pendorong untuk meningkatkan kualitas kerja organisasi.

Berdasarkan beberapa teori yang telah dikemukakan dapat diambil sintesis bahwa budaya organisasi adalah sistem nilai dan norma yang diyakini dan diterima berdasarkan persepsi anggota organisasi yang mampu mempengaruhi tindakan dan perilakunya di dalam organisasi.

\section{METODOLOGI PENELITIAN}

Penelitian ini bertujuan untuk mendeskripsikan hubungan dari variabel efektivitas sistem informasi manajemen dan budaya organisasi secara bersama-sama dengan produktivitas kerja dosen di Universitas Muhammadiyah Sukabumi. Metode yang digunakan dalam penelitian ini 
adalah metode survei dengan pendekatan korelasional. Populasi dalam penelitian ini adalah semua dosen yang berstatus dosen tetap di Universitas Muhammadiyah Sukabumi, yang berjumlah 134 dosen. Jumlah sampel dalam penelitian ini adalah 101 dosen yang ditetapkan menggunakan rumus Taro Yamane. Uji coba instrumen dilakukan melalui teknik korelasi Product Moment Pearson. Uji Reliabilitas instrumen penelitian menggunakan perhitungan Alpha Cronbach. Sedangkan analisis data menggunakan statistik inferensial dengan menggunakan uji analisis varians regresi.

\section{HASIL PENELITIAN}

\section{Pengujian Persyaratan Analisis}

\section{Uji Normalitas}

Pengujian normalitas terhadap galat taksiran produktivitas kerja dosen atas efektivitas sistem informasi manajemen dan budaya organisasi menggunakan uji Lilliefors. Hasil analisis uji normalitas dapat disajikan pada tabel 17, berikut:

Tabel 17. Hasil Uji Normalitas Data menggunakan rumus Lilliefors

\begin{tabular}{crccl}
\hline No & Galat & Lo maks & $\mathbf{L}_{\mathbf{t}(\mathbf{0}, 05: 101)}$ & Kesimpulan \\
\hline 1 & Variabel Y- $\hat{Y}_{1}$ & 0,0850 & 0,0881 & Berdistribusi Normal \\
\hline 2 & Variabel Y- $\hat{Y}_{2}$ & 0,0792 & 0,0881 & Berdistribusi Normal \\
\hline
\end{tabular}

Persyaratan normal: $\mathbf{L}_{\mathbf{0}}$ maks $<\mathbf{L}_{\mathbf{t}}$

Dari hasil perhitungan yang disajikan pada tabel di atas, dapat dinyatakan bahwa data dari semua variabel dalam penelitian ini berdistribusi normal, karena $t_{\text {hitung }}$ untuk semua variabel berada pada daerah penerimaan hipotesis nol. Dengan demikian persyaratan normalitas dalam penelitian ini dapat terpenuhi.

\section{Uji Homogenitas}

Homogenitas diuji dengan menggunakan uji Barlett, data variabel produktivitas kerja dosen ( $\mathrm{Y}$ ) atas variabel efektivitas sistem informasi manajemen $\left(\mathrm{X}_{1}\right)$, berdasarkan hasil perhitungan diperoleh nilai $\left(\chi^{2}\right.$ hitung) sebesar 49,497, sedangkan nilai tabel $\chi_{(0,95 ; 54)}^{2}$ sebesar 72,153 , karena $\chi^{2}$ hitung $<\chi^{2}$ tabel, dapat disimpulkan bahwa sebaran data variabel terikat (Y) yang dikelompokkan berdasarkan nilai variabel bebas $\left(\mathrm{X}_{1}\right)$ berasal dari populasi yang homogen. Selanjutnya, data variabel produktivitas kerja dosen $(\mathrm{Y})$ atas budaya organisasi $\left(\mathrm{X}_{2}\right)$, berdasarkan hasil perhitungan diperoleh nilai $\left(\chi^{2}\right.$ hitung $)$ sebesar 38,788 , sedangkan nilai tabel $\chi_{(0,95 ; 55)}^{2}$ sebesar 73,311, karena $\chi^{2}{ }_{\text {hitung }}<\chi_{\text {tabel }}^{2}$, dapat disimpulkan bahwa sebaran data variabel terikat $(\mathrm{Y})$ yang dikelompokkan berdasarkan nilai variabel bebas $\left(\mathrm{X}_{2}\right)$ berasal dari populasi yang homogen.

\section{Pengujian Hipotesis}

\section{Hubungan antara Efektivitas Sistem Informasi Manajemen $\left(\mathrm{X}_{1}\right)$ dengan Produktivitas Kerja Dosen (Y)}

Hasil pengujian signifikansi persamaan regresi pada tabel 12, diperoleh nilai $F_{\text {hitung }}$ $=13,14$ dan $\mathrm{F}_{\text {tabel }}(0,05 ; 99)=3,94$, atau $\mathrm{F}_{\text {tabel }(0,01 ; 99)}=6,90$, karena $\mathrm{F}_{\text {hit }}>\mathrm{F}_{\text {tab }}$ maka regresi antara efektivitas sistem informasi manajemen $\left(\mathrm{X}_{1}\right)$ dengan produktivitas kerja dosen $(\mathrm{Y})$ yang mengikuti persamaan regresi $\hat{Y}=64,05+0,280 X_{1}$ sangat signifikan. Dengan demikian persamaan tersebut dapat digunakan untuk menjelaskan model hubungan variabel 
produktivitas kerja dosen (Y) melalui variabel efektivitas sistem informasi manajemen $\left(\mathrm{X}_{1}\right)$ dimana setiap peningkatan 1 unit efektivitas sistem informasi manajemen akan meningkatkan produktivitas kerja dosen sebesar 0,280 unit. Hasil perhitungan koefisien korelasi antara variabel $\mathrm{X}_{1}$ dengan $\mathrm{Y}$, diperoleh $\left(\mathrm{r}_{\mathrm{y} 1}\right)$ sebesar 0,342 , Artinya terdapat hubungan positif antara efektivitas sistem informasi manajemen dengan produktivitas kerja dosen sebesar 0,342.

Hasil uji signifikansi koefisien korelasi menunjukkan bahwa $t_{\text {hitung }}=3,623$ dan $t_{\text {tabel }}(0,05 ; 99)$ $=1,980$, karena $t_{\text {hit }}>t_{\text {tab }}$ maka dapat disimpulkan bahwa hubungan antara variabel efektivitas sistem informasi manajemen dengan variabel produktivitas kerja dosen adalah signifikan. Dengan demikian, hipotesis nol $\left(\mathrm{H}_{0}\right)$ ditolak dan hipotesis alternatif $\left(\mathrm{H}_{1}\right)$ diterima, artinya, terdapat hubungan positif yang signifikan antara efektivitas sistem informasi manajemen dengan produktivitas kerja dosen..

\section{Hubungan antara Budaya organisasi $\left(\mathbf{X}_{2}\right)$ dengan Produktivitas Kerja Dosen $(\mathbf{Y})$}

Hasil pengujian signifikansi persamaan regresi pada tabel 14, diperoleh $F_{\text {hitung }}=11,86$ dan $\mathrm{F}_{\text {tabel }(0,05 ; 99)}=3,94$, atau $\mathrm{F}_{\text {tabel }(0,01 ; 99)}=6,90$, karena $\mathrm{F}_{\text {hit }}>\mathrm{F}_{\text {tab }}$ maka regresi antara budaya organisasi $\left(\mathrm{X}_{2}\right)$ dengan produktivitas kerja dosen $(\mathrm{Y})$ yang mengikuti persamaan regresi $\hat{\mathrm{Y}}=$ $65,39+0,30 X_{2}$ sangat signifikan. Dengan demikian persamaan tersebut dapat digunakan untuk memprediksi nilai produktivitas kerja dosen $(\mathrm{Y})$ melalui nilai budaya organisasi $\left(\mathrm{X}_{2}\right)$, dimana setiap peningkatan 1 unit budaya organisasi akan meningkatkan produktivitas kerja dosen sebesar 0,30 unit.

Hasil perhitungan koefisien korelasi antara variabel $\mathrm{X}_{2}$ dengan $\mathrm{Y}$, diperoleh $\left(\mathrm{r}_{\mathrm{y} 2}\right)$ sebesar 0,327, Artinya terdapat hubungan positif antara budaya organisasi dengan produktivitas kerja dosen sebesar 0,327 dengan kategori sedang. Hasil uji signifikansi menunjukkan bahwa thitung $=3,441$ dan $t_{\text {tabel }(0,05 ; 99)}=1,98$, karena $t_{\text {hitung }}>t_{\text {tabel }}$ maka dapat disimpulkan bahwa hubungan antara variabel budaya organisasi dengan produktivitas kerja dosen adalah signifikan.

\section{Hubungan antara Efektivitas sistem informasi manajemen $\left(\mathrm{X}_{1}\right)$ dan Budaya organisasi $\left(\mathbf{X}_{2}\right)$ secara bersama-sama dengan Produktivitas Kerja Dosen ( $\left.\mathbf{Y}\right)$}

Hasil menunjukkan bahwa uji signifikansi untuk korelasi ganda diperoleh $t_{\text {hitung }}=7,630$, dan nilai tabel $t_{\text {tabel }(0,05)}$ sebesar 3,089, atau $t_{\text {tabel }(0,01)}$ sebesar 4,829, hal ini berarti bahwa terdapat hubungan positif sangat signifikan antara efektivitas sistem informasi manajemen $\left(\mathrm{X}_{1}\right)$ dan budaya organisasi $\left(\mathrm{X}_{2}\right)$ secara bersama-sama dengan produktivitas kerja dosen $(\mathrm{Y})$. Adapun besarnya kontribusi efektivitas sistem informasi manajemen dan budaya organisasi secara bersama-sama terhadap produktivitas kerja dosen sebesar 13,5\%.

Mencermati nilai koefisien korelasi ganda dan bila membandingkannya dengan kedua koefisien korelasi sederhana, terlihat bahwa antara variabel efektivitas sistem informasi manajemen $\left(\mathrm{X}_{1}\right)$ dan variabel budaya organisasi $\left(\mathrm{X}_{2}\right)$ terjadi efek yang saling menguatkan (sinergis) dalam hubungannya dengan produktivitas kerja dosen. Hal ini terlihat dari nilai koefisien ganda $\left(\mathrm{r}_{\mathrm{y} 12}\right)$ sebesar 0,367 yang lebih besar dari nilai koefisien korelasi sederhana antara efektivitas sistem informasi manajemen dengan nilai produktivitas kerja dosen $\left(\mathrm{r}_{\mathrm{y} 1}\right)$ sebesar 0,342, sementara nilai koefisien korelasi antara budaya organisasi dengan produktivitas kerja dosen $\left(\mathrm{r}_{\mathrm{y} 2}\right)$ sebesar 0,327

\section{Uji korelasi parsial}

Berdasarkan data di atas menunjukkan bahwa kekuatan hubungan antara variabel efektivitas sistem informasi manajemen $\left(\mathrm{X}_{1}\right)$ terhadap variabel produktivitas kerja dosen $(\mathrm{Y})$ lebih tinggi dibandingkan dengan kekuatan variabel budaya organisasi $\left(\mathrm{X}_{2}\right)$ terhadap variabel produktivitas kerja dosen (Y), dengan demikian dalam penelitian ini variabel efektivitas sistem 
informasi manajemen $\left(\mathrm{X}_{1}\right)$ merupakan variabel utama dan memberikan kontribusi terbesar terhadap variabel produktivitas kerja dosen $(\mathrm{Y})$.

\section{PEMBAHASAN}

\section{Hubungan antara Efektivitas Sistem Informasi Manajemen ( $\left.\mathrm{X}_{1}\right)$ dengan Produktivitas Kerja Dosen (Y)}

Kekuatan hubungan antara efektivitas sistem informasi manajemen dengan produktivitas kerja dosen dapat ditunjukkan oleh koefisien korelasi $\mathrm{r}_{\mathrm{y} 1}=0,342$. Hasil uji signifikansi koefisien korelasi menunjukan bahwa koefisien korelasi antara efektivitas sistem informasi manajemen dengan produktivitas kerja dosen sangat sangat signifikan $\left(F_{\text {hit }}=13,14>F_{\text {tab }}=\right.$ $6,90)$ dengan taraf signifikansi $(\alpha=0,01)$. Dengan demikian, terdapat hubungan positif yang sangat signifikan antara efektivitas sistem informasi manajemen dengan produktivitas kerja dosen. Koefisien diterminasi korelasi $\mathrm{r}_{\mathrm{y} 1}^{2}=0.117$ menunjukkan bahwa kontribusi efektivitas sistem informasi manajemen sebesar $11,7 \%$, adapun $88,3 \%$ berasal dari variabel yang lain. Hubungan fungsional antara efektivitas sistem informasi manajemen dengan produktivitas kerja dosen mengandung makna bahwa semakin tinggi dorongan dari efektivitas sistem informasi manajemen terhadap produktivitas kerja dosen maka akan semakin tinggi pula tingkat produktivitas kerja dosen dalam melaksanakan tugas-tugasnya sebagai seorang dosen.

Sejalan dengan hasil penelitian Naidah (2009:41) yang menunjukan bahwa variabel sistem informasi manajemen berpengaruh positif terhadap kinerja karyawan pada PT. Metro Batavia Air Distrik Makassar. Haliso dan Laja-Ademola, Toyosi (2013:39) mengemukakan penelitiannya yang menunjukkan bahwa ada hubungan positif antara ketersediaan sumber informasi dan produktivitas akademik dosen serta hubungan yang signifikan antara pemanfaatan sumber informasi dan produktivitas akademik dosen. Kualitas pengajaran, penelitian, dan publikasi dosen tergantung pada kualitas sumber informasi dan layanan yang digunakan oleh mereka. Ketika sumber informasi berkualitas tersedia dan dosen menempatkannya untuk digunakan secara efektif, maka peoduktivitas akademik dosen dapat meningkat.

Berdasarkan uraian di atas, maka efektivitas sistem informasi manajemen merupakan salah satu faktor penentu dalam meningkatkan produktivitas kerja dosen. Dengan demikian penelitian ini mengkonfirmasi bahwa terdapat hubungan positif sangat signifikan antara efektivitas sistem informasi manajemen dengan produktivitas kerja dosen.

\section{Hubungan antara Budaya organisasi $\left(\mathbf{X}_{2}\right)$ dengan Produktivitas Kerja Dosen (Y)}

Kekuatan hubungan antara budaya organisasi dengan produktivitas kerja ditunjukkan oleh koefisien korelasi $\mathrm{r}_{\mathrm{y} 2}$ sebesar 0,327. Berdasarkan nilai koefisien korelasi. Hasil uji signifikansi koefisien korelasi menunjukan bahwa antara budaya organisasi dengan produktivitas kerja sangat signifikan $\left(\mathrm{F}_{\text {hit }}=11,86>\mathrm{F}_{\mathrm{tab}(0,05)}=3,94\right)$ atau $\left(\mathrm{F}_{\text {hit }}=11,86>\mathrm{F}_{\text {tab }(0,01)}\right.$ $=6,90$ ). Dengan demikian terdapat hubungan positif sangat signifikan antara variabel budaya organisasi dengan produktivitas kerja dosen. Besarnya koefisien diterminasi $\left(r^{2}{ }^{2}\right)$ antara budaya organisasi dengan produktivitas kerja dosen sebesar 0.107 , hal ini berarti $10,7 \%$ produktivitas kerja dosen dapat dihasilkan dari adanya budaya organisasi, adapun $89,3 \%$ berhubungan dengan variabel yang lain.

Sejalan dengan hasil penelitian Ihsani, Syarif, Hayati. (2017: 43) menunjukan budaya rganisasi dapat mempengaruhi turun naiknya produktivitas kerja sebesar 30,14\%, membuktikan terdapat hubungan positif antara budaya organisasi dengan produktivitas kerja. Penelitian Aries dan Dewi (2013:37) mengemukakan budaya organisasi memberikan kontribusi terbesar sebesar $80 \%$ berpengaruh dominan terhadap produktivitas kerja karyawan. 
Budaya organisasi mempengaruhi tinggi rendahnya produktivitas kerja anggota organisasi yang ada didalamnya karena membentuk sikap, tindakan dan perilaku didalam melaksanakan tugas dan fungsinya

Berdasarkan uraian di atas, maka budaya organisasi merupakan salah satu faktor penentu dalam meningkatkan produktivitas kerja dosen. Dengan demikian penelitian ini mengkonfirmasi bahwa terdapat hubungan positif yang signifikan antara budaya organisasi dengan produktivitas kerja dosen.

\section{Hubungan antara Efektivitas sistem informasi manajemen $\left(\mathrm{X}_{1}\right)$ dan Budaya organisasi $\left(\mathrm{X}_{2}\right)$ secara bersama-sama dengan Produktivitas Kerja Dosen ( $\mathrm{Y}$ )}

Berdasarkan hasil analisis data tentang kekuatan hubungan antara variabel bebas dengan variabel terikat dapat dijelaskan bahwa kekuatan hubungan antara variabel efektivitas sistem informasi manajemen $\left(\mathrm{X}_{1}\right)$ dan budaya organisasi $\left(\mathrm{X}_{2}\right)$ secara bersama-sama dengan produktivitas kerja dosen $(\mathrm{Y})$, diperolah nilai $\mathrm{F}_{\text {hitung }}=7,526$ dan nilai $\mathrm{F}_{\text {tabel }(0,05)}=3,08$, atau $\mathrm{F}_{\text {tabel }(0,01)}=4,82$, karena $\mathrm{F}_{\text {hitung }}>\mathrm{F}_{\text {tabel}}$, dalam taraf signifikansi $\alpha=0,05$ dan 0,01 , ini bermakna bahwa variabel bebas yang diteliti dapat dipergunakan untuk memprediksi variabel terikat, Bila variabel bebas dihubungkan secara bersama-sama dengan variabel terikat diperoleh koefisien korelasi $r_{\mathrm{y} 12}$ sebesar 0,367 , koefisien determinasi $\mathrm{r}_{\mathrm{y} 12}^{2}=0,135$, hal ini menunjukkan bahwa variabel efektivitas sistem informasi manajemen dan budaya organisasi secara bersama-sama terhadap produktivitas kerja dosen berkontribusi sebesar 13,5\%. Namun apabila variabel budaya organisasi $\left(X_{2}\right)$ dikontrol diperoleh $r_{y 12}=0,314$, koefisien determinasi $r_{y 12}^{2}=0,099$, artinya variabel efektivitas sistem informasi manajemen terhadap produktivitas kerja dosen (budaya organisasi dikontrol) berkontribusi sebesar 9,9\% dan jika variabel efektivitas sistem informasi manajemen $\left(X_{1}\right)$ dikontrol maka diperoleh koefisien korelasi $r_{\mathrm{y} 21}=0,230$ dan koefisien determinasi $r^{2}{ }_{y 21}=0,053$ artinya variabel budaya organisasi terhadap produktivitas kerja dosen (efektivitas sistem informasi manajemen dikontrol) berkontribusi sebesar 5,3\%.

Peretomode dan Chukwuma (2012:18) mengemukakan "the lecturer's productivity defined in terms of research output or publications in referred national and international journals and text books. Some of these lecturers have participated in self-sponsored development activities and few others have benefited from their institution's sponsored staff development programmes". Dengan demikian, produktivitas kerja dosen merupakan hasil kerja atau output dosen yang dikaitkan waktu, kuantitas dan kualitas dalam menjalankan tugasnya melaksanakan tridharma perguruan tinggi yang mencakup pendidikan dan pengajaran, penelitian serta pengabdian kepada masyarakat.

Untuk melihat seberapa besar kekuatan hubungan antara variabel bebas dan variabel terikat serta untuk mendapatkan solusi optimal dari penelitian ini dapat dilihat pada gambar konstelasi penelitian dan statistik berdasarkan Teori Pengenalan Ilmiah untuk Riset Operasi di bidang Manajemen Pendidikan atau dikenal dengan SITOREM ( Hardhienata, 2017) seperti ditunjukkan pada gambar 2 berikut: 


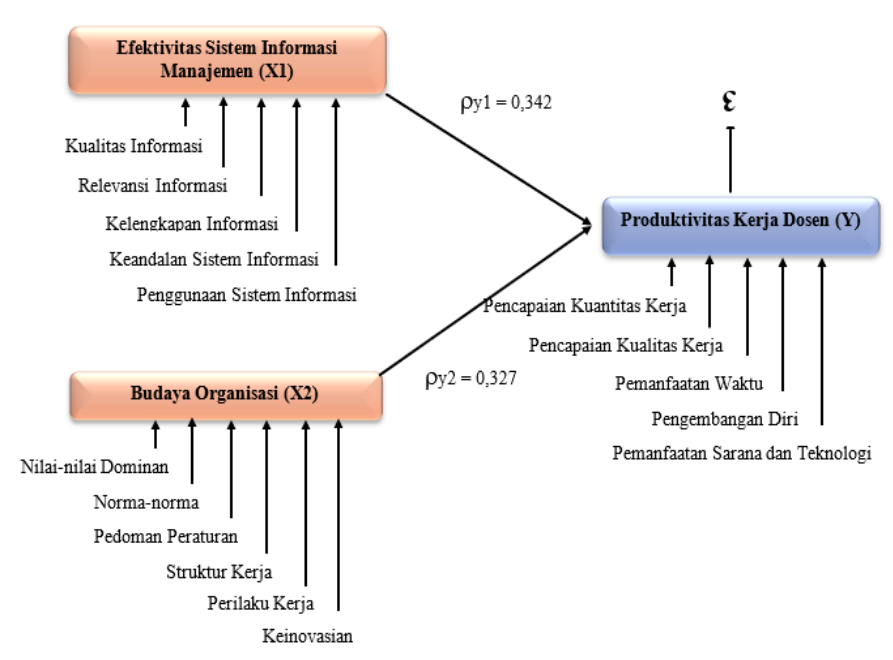

Gambar 2. Model Optimaziation SITOREM
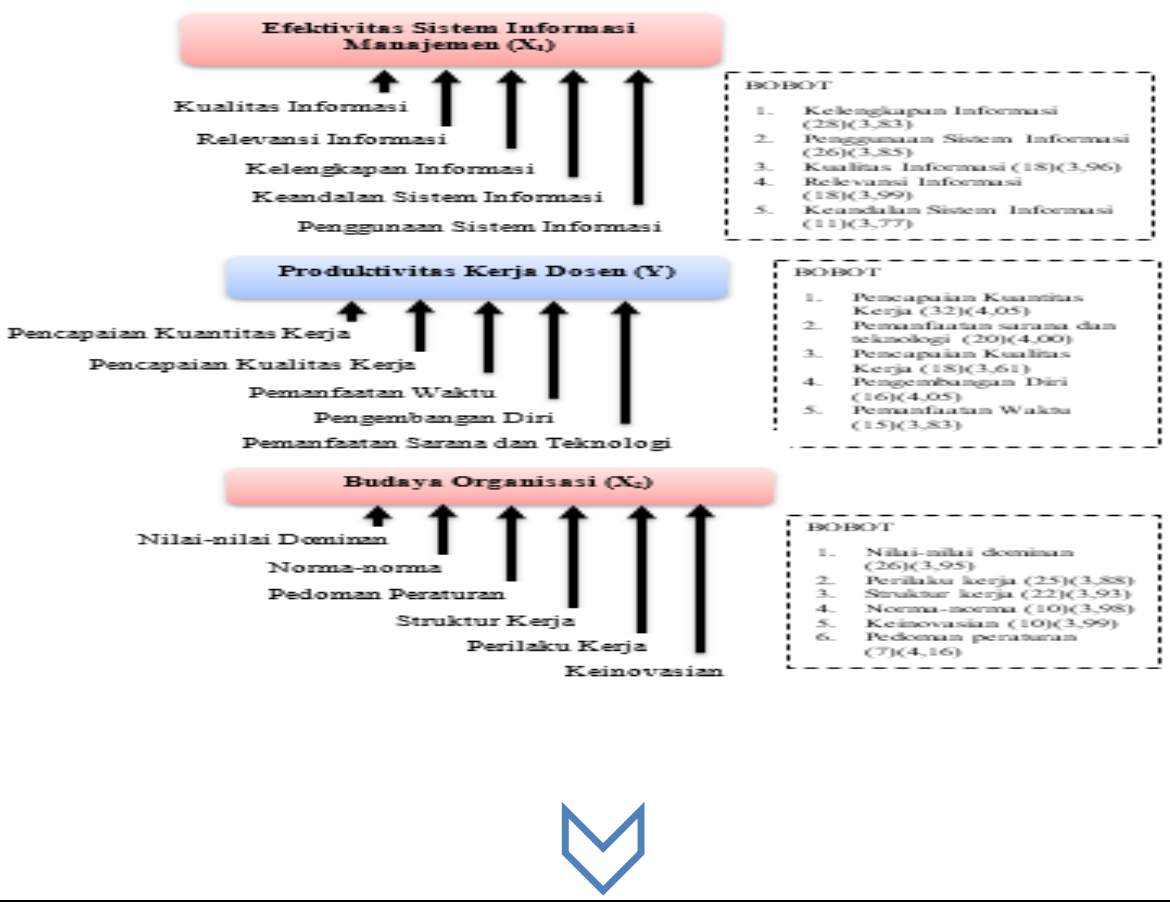

\section{PRIOR ITAS UNTUK DITINGKATKAN}

1. Kelengkapan Informasi $(28)(3,83)$

2. Penggunaan Sistem Informasi $(26)(3,85)$

3. Nilai-nilai dominan $(26)(3,95)$

4. Perilaku kerja $(25)(3,88)$

5. Struktur kerja $(22)(3,93)$

6. Kualitas Informasi $(18)(3,96)$

7. Relevansi Informasi $(18)(3,99)$

8. Pencapaian Kualitas Kerja $(18)(3,61)$

9. Pemanfaatan Waktu $(15)(3,83)$

10. Keandalan Sistem Informasi $(11)(3,77)$

11. Norma-norma $(10)(3,98)$

12. Keinovasian $(10)(3,99)$

Gambar 3. Model Optimasi SITOREM 


\section{SIMPULAN}

Hasil analisis membuktikan bahwa terdapat hubungan yang positif antara efektivitas sistem informasi manajemen dan budaya organisasi baik sendiri-sindiri maupun secara bersama-sama dengan produktivitas kerja dosen. Hal ini mencerminkan bahwa untuk meningkatkan produktivitas kerja dosen dapat dilakukan dengan cara meningkatkan efektivitas sistem informasi manajemen dan perbaikan budaya organisasi.

\section{REFERENSI}

Aceng Muhtaram Mirfani dan Suryadi. 2010. Pengelolaan Pendidikan: Bab 7 Sistem Informasi Manajemen. Bandung: Tim Administrasi Pendidikan Fakultas Ilmu Pendidikan Universitas Pendidikan Indonesia

Badeni. 2014. Kepemimpinan dan Perilaku Organisasi. Bandung: Alfabeta

Bambang S. Joko. 2010. Sistem Informasi Perguruan Tinggi dalam Bidang Pendataan Pendidikan Tinggi. Jurnal Pendidikan dan Kebudayaan, Vol. 16 nomor 2, Maret 2010.

Bilson Simamora. 2002. Panduan Riset Perilaku Konsumen. Jakarta: PT. Gramedia Pustaka Utama.

Engkoswara dan Aan Komariah. 2010. Administrasi Pendidikan. Bandung: Alfabeta

Hidayat Rais, Henny Suharyati, Yuyun Elizabeth Patras, Sutji Harjanto, Haposan Andi. 2018. Optimalisasi Budaya Mutu Sekolah Untuk Meningkatkan Komitmen Guru. Jurnal Manajemen Pendidikan, Vol. 6 No. 1

Irham Fahmi. 2013. Manajemen Kinerja Teori dan Aplikasi. Bandung: Alfabeta

Ismail Solihin. 2009. Pengantar Manajemen. Jakarta: Penerbit Erlangga

Khaerul Umam. 2012. Perilaku Organisasi. Bandung: CV. Pustaka Setia

Laudon, Kenneth C. dan Laudon, Jane P. 2008. Sistem Informasi Manajemen. Terjemahan Chriswan Sungkono dan Machmudin Eka P. Edisi 10. Jakarta : Salemba Empat

McLeod, Raymond Jr. dan George P. Schell. 2008. Sistem Informasi Manajemen. Terjemahan: Ali Akbar Yulianto. Jakarta: Salemba Empat.

Muchdarsyah Sinungan. 2000. Produktivitas Apa dan Bagaimana. Jakarta: Bumi Aksara

Organisasi Dengan Produktivitas Kerja Karyawan Pada PT. Mitra Konservasi Indonesia (Cico Resort). E-journal tersedia

http://jom.unpak.ac.id/index.php/ilmumanajemen/article/download/621/572. Diakses 17 Januari 2018

Rabiyannur Lubis. 2012. Hubungan Antara Disiplin Kerja dan Motivasi Kerja dengan Produktivitas Kerja Dosen di Lingkungan Universitas Islam "45” Bekasi. Jurnal Turats, Vol. 8, No. 1, Januari 2012, hlm 68-78. Tersedia: http://id.portalgaruda.org/?ref=browse\&mod=viewarticle\&article=19629. Diakses 01 April 2018

Sedarmayanti. 2007. Manajemen Sumber Daya Manusia: Reformasi Birokrasi dan Manajemen Pegawai Negeri Sipil. Bandung: Refika Aditama

Sedarmayanti. 2009. Sumber Daya Manusia dan Produktivitas Kerja. Bandung: CV. Mandar Maju.

Soewarto Hardhienata. 2017. The development of scientific identification theory to conduct operation research in education management. IOP Conference Series: Materials Science and Engineering. Volume 166.

Sondang P. Siagian. 2001. Manajemen Sumber Daya Manusia. Jakarta: Bumi Aksara Sondang P. Siagian. 2009. Kiat Meingkatkan Prodktivitas Kerja. Jakarta: Rineka Cipta 
Suwena, Kadek Rai, The Administrator's Production Function sebagai Sebuah Pendekatan Penilaian Produktivitas Pelaksanaan Proses Belajar Mengajar Dosen pada Perguruan Tinggi. E-jurnal http://www. ejournal.undiksha.ac.id. diakses 17 Januari 2018

Widjaja. 2006. Administrasi Kepegawaian. Bandung: Rajawali 